\title{
Oral lymphangioma
}

\author{
Mohammed Said Hamed* \\ Dean and Head of Oral and Maxillofacial Surgery, Gulf Medical University, United Arab Emirates
}

Received: October 23, 2017; Published: October 26, 2017

*Corresponding author: Mohammed Said Hamed, College of Dentistry, Gulf Medical University, Ajman, United Arab Emirates, Consultant Maxillofacial Surgeon, Thumbay Hospital, Ajman, United Arab Emirates, Tel: +971556139380; Email: prof.mohamedsaidhamed@gmu.ac.ae

\begin{abstract}
Lymphangioma is a benign tumor involving lymphatic channels. They are common among the tumors occurring in the head and neck region but intraoral lymphangioma are rare in occurrence. in this mini review an attempt has been made to describe in brief the etiopathogenesis, clinical features, differential diagnosis, histopathological features, imaging features and treatment of this condition.
\end{abstract}

Keywords: Lymphangioma; Intraoral; Tongue

\section{Introduction}

Lymphangioma is a benign tumors involving lymphatic channels and is mostly confined in the head and neck region in about majority of cases [1,2]. Lymphangiomas occur commonly at birth or before the age of two [3]. In the oral cavity anterior two-thirds of the tongue is most commonly involved site [4]. Some syndrome and conditions like Turner syndrome, Noonan syndrome, trisomies, cardiac anomalies, and fetal alcohol syndrome are commonly associated with Lymphangiomas [3] with this background an attempt has been made to briefly review the features of oral lymphangiomas.

\section{Review Findings}

Lymphangiomas are classified according to the vessels diameter into: capillary or micro cystic, cavernous or macro cystic and cystic or hygroma lymphangioma [5]. The etiopathogenesis of lymphangiomas have been explained on the basis of two possible theories [6]. The first one elucidates that the lymphatic system progress from five primitive sacs of venous system and endothelial out pouching spread from jugular sac centrifugally to form the lymphatic system. The second school if thinking states that the lymphatic system develops from mesenchymal clefts in the venous plexus reticulum and spread centripetally toward the jugular sac [6-8]. Although lymphangiomas commonly occur in the head and neck region, intraoral lymphangiomas are rare [9]. Among the intraoral sites the dorsum of the tongue is commonly involved [9]. Clinical examination of the lymphangiomas usually reveals a slow growing, painless soft tissue mass. The lesions of lymphangioma may be located superficially superficial or within deeper tissues $[10,11]$.

Clinically superficial lesions demonstrate as elevated nodules, pink or yellow color or appear as transparent grouped vesicles, further course of time due to secondary hemorrhage become the lesion becomes reddish or purple. On the other hand the deeper lesions show as soft, diffuse masses with normal color $[10,11]$. Oral lymphangiomas involving the anterior two-thirds of the tongue frequently cause macroglossia [12].The involved tongue surface demonstrates a pebbly surface, appearing like a cluster of translucent vesicles and is often referred to as frog eggs or tapioca pudding appearance. Deeper lesions on the tongue present as soft, ill-defined masses resulting in macroglossia [12]. Though lymphangioma is a benign tumor it may infrequently lead to difficulties due to its penetrating nature, unlimited demarcation, and involvement of surrounding vital structures [12].

The diagnosis of lymphangioma based on a combination of classical clinical features histopathological examination and some imaging methods. Commonly used imaging modalities are ultrasound and angiography [13]. Precise demarcation of extension of the lesion is needed for surgical planning [14]. Ultrasound imaging usually exhibits unilocular or multilocular cystic masses with smooth, thin/ thick or irregular walls [14]. Lymphangioma is isointense to muscle on T1-weighted and hyperintense to fat on T2-weighted Magnetic resonance (MR) images. Researchers have stated that MR imaging delineates the tumor lesion extension more clearly than ultrasound and Computerized tomography (CT) scans [15]. Angiography also plays important role in diagnosis of Lymphangioma because ultrasonography tends to usually detect the cystic nature and fluid component of a lymphangioma whereas angiography will rule out vascular lesions [16]. The list of possible differential diagnosis is commonly considered for oral Lymphangioma include hemangioma, lingual thyroid, granular cell tumor and infectious swellings [17].

Histological Lymphangioma exhibit propagation of lymphatic vessels with lymph in the vessels with erythrocytes and lymphocytes. 
The superficial lesion consists of distended lymph vessels lined by flat endothelial cells in a intermittent layer immediately subjacent to the oral epithelium. Deeper lesion shows uneven, widened, and interconnected lymphatic vessels [18]. Advanced investigative methods include detection of definite antibodies for lymphatic endothelium are VEGR3 (vascular endothelial growth factor receptor 3), podoplanin, lymphatic vessel endothelial HA receptor-1 (LYVE-1), Prox1 and D2-40, Podoplanin and D2-40 monoclonal antibody. These factors aid in distinguishing lymphatic endothelial cells from blood vessels.[14] Several treatment modalities have been used for the treatment of lymphangiomas. The important treatment modalities include surgical excision, radiation therapy, cryotherapy, electrocautery, sclerotherapy, steroid administration, ligation, and laser surgery [19].

Conventional management involves surgical elimination of involved tissue without harming vital structures. Due to the anatomical complexity of the head and neck, surgical option can be cosmetically and/or functionally morbid at times As a result of this, nonsurgical therapies like diathermy, cryotherapy, radiation therapy, fibrin glue, and percutaneous sclerosants have gained popularity.[20] Sclerosants that have been used include sodium morrhuate, dextrose, hypertonic saline, tetracycline, doxycyline, acetic acid, ethanol, boiling water, and OK-432 [20]. Factor OK432, a protein derived from a culture of Streptococcus pyogenes has been fairly successful in the treatment of Lymphangioma.. The OK432 leads to augmented endothelial porousness and lymph drainage through white blood cell activation and cytokine production [20].

The main benefit of OK-432 over other sclerosing agents is the lack of perilesional fibrosis [21]. Another important treatment modality is cryotherapy and has been observed that lymphangiomas are very suitable for treatment by cryosurgery because of their elevated fluid content and reduced blood supply [22]. In majority of the cases lymphangiomas have a good prognosis, when they do not involve important structures. However important structures are involved the treatment must be more conservative for a better life quality of the patient [23]. Some of the researchers have noted a higher rate of recurrence (as high as $39 \%$ ) in cases of infiltrative lymphangiomas [24].

\section{Conclusion}

Although lymphnagioma is benign in nature and its occurrence in the oral cavity is extremely rare, it is important that a health care provider like dentist is conscious of the existence of such lesion in order to promote a precise diagnosis, and therefore, a proper treatment can be rendered for this disorder.

\section{References}

1. Dogan N, Durmaz CE, Sencimen M, Ucok O, Okcu MK, et al. (2010) The Treatment of Recurrent Lymphangioma in the Oral Buccal Mucosa by Cryosurgery: A Case Report. OHDMBSC 9(1): 7-10.

2. Mandel L (2004) Journal of Oral and Maxillofacial Surgery 62(10): 1320-1323.
3. Neville BW, Damm DD, Allen CM, Bouquot JE (2002) Soft tissue tumors. In: Oral \& Maxillofacial Pathology ( $2^{\text {nd }}$ edn) Philadelphia, PA: WB Saunders pp. 475-477.

4. Stănescu L, Georgescu EF, Simionescu C, Georgescu I (2006) Lymphangioma of the oral cavity. Rom J Morphol Embryology 47(4): 373-377.

5. Weiss SW, Goldblum JR (2001) Tumors of lymph vessels. In: Soft tissue tumors ( $4^{\text {th }}$ edn) St. Luis: Mosby pp. 955-967.

6. Suen JY, Waner M (1989) Treatment of oral cavity vascular malformations using the neodymium: YAG laser. Arch Otolaryngol Head Neck Surg 115: 1329-1333.

7. Hong JP, Lee MY, Kim EK, Seo DH (2009) Giant Lymphan-gioma of the tongue. J craniofac Surg 20: 252-254.

8. Jian XC (2005) Surgical management of lymphangiomatous or lymphangiohemangio matous macroglossia. J Oral Maxillofac Surg 63: 15-19.

9. Gaddikeri K, Bhorgonde DD (2016) Lymphangioma of the tongue- a rare case report and review of the literature. Asian Pac J Health Sci 3(4): 285287.

10. Goswami M, Singh S, Gokkulakrishnan S, Singh A (2011) Lymphangioma of the tongue. National Journal of Maxillofacial Surgery 2(1): 86-88.

11. Bhayya H, Pavani D, Avinash Tejasvi ML, Geetha P (2015) Oral lymphangioma: A rare case report. Contemporary Clinical Dentistry 6(4): 584-587.

12. Sunil S, Gopakumar D, Sreenivasan BS (2012)Oral lymphangioma - Case reports and review of literature . Contemp Clin Dent 3(1): 116-118.

13. Yoganna SS, Prasad RGR, Sekar B (2014) Oral lymphangioma of the buccal mucosa a rare case report. J Pharm Bioal Sci 6(1): S188.

14. Kaur M, Gombra V, Subramanyam RV, Hasan S (2015) Lymphangioma of the buccal mucosa - A case report and review of literature. J Oral Med Oral Surg Oral Pathol Oral Radiol 1(3): 123-125.

15. Pui MH, Li ZP, Chen W, Chen JH (1997) Lymphangioma: imaging diagnosis, Australas Radiol 41(4): 324-338.

16. Yoganna SS, Prasad RGR, Sekar S (2014) J Pharm Bioallied Sci 6(Suppl 1): S188-S191.

17. Chakravarti A, Bhargava R (2013) Lymphangioma circumscriptum of the tongue in children: Successful treatment using intralesional bleomycin. Int J Pediatr Otorhinolaryngol 77(8): 1367-1369.

18. Pammar C, Kotrashetti VS, Nayak R, Hosmani J (2015) Lymphangioma of the buccal mucosa: A case report with a literature review. J Orofac Sci 7: 129-131.

19. Suen J, Waner M (1989) Treatment of oral cavity vascular malformations using the Meodymium: YAG laser. Arch Otolaryngol Head Neck Surg 9: 115-132.

20. Jason L Acevedo, Shah R, Scott E Brietzke (2008) Nonsurgical therapies for lymphangiomas: A systematic review. Otolaryngology-Head and Neck Surgery 138: 418-424.

21. Okazaki T, Iwatani S, Yanai T, Kobayshi H, Kato Y, et al. (2007) Treatment of lymphangioma in children: our experience of 128 cases. Journal of Pediatric Surgery 42(2): 386-389.

22. Bekke JP, Baart JA (1979) Six years' experience with cryosurgery in the oral cavity. International Journal of Oral Surgery 8: 251-270.

23. Lucena LP, Bonan PRF, Costa ALP, Carvalho LPB, Ferreira VY, et al. (2016) Lymphohemangioma on Hard Palate: Case Report. J Clin Case Rep 6: 812.

24. Orvidas LJ, Kasperbauer JL (2000) Pediatric lymphangiomas of the head and neck. Ann Otol Rhinol Laryngol 109: 411-421. 


\begin{tabular}{ll} 
BIOMEDICAL & Assets of Publishing with us \\
RESEARCHES & - Global archiving of articles \\
\hline & - Immediate, unrestricted online access \\
\hline
\end{tabular}

